\title{
Influence of operating pressure on concentration polarization layer resistance in revers osmosis
}

\section{Serhii Huliienko, Oksana Leshchenko}

\author{
National Technical University of Ukraine "Igor Sikorsky Kyiv Polytechnic \\ Institute", Kyiv, Ukraine
}

Keywords:

Osmosis

Membrane

Resistance

Polarization

Flux

Pressure

\section{Article history:}

Received

21.09.2018

Received in revised form 27.10.2018

Accepted

28.03.2019

\section{Corresponding} author:

Serhii Huliienko

E-mail:

gunder@i.ua

DOI:

$10.24263 / 2304-$

974X-2019-8-1-13

\section{Abstract}

Introduction. The experimental examination of hypothesis about linear dependence of concentration polarization resistance from pressure was carried out and the influence of hydrodynamic condition on this resistance is determined.

Materials and methods. The research was carried out with using of commercially available membrane modules TFC-75 type. The measurements of productivity were carried out with using of deionized water (total dissolved solids $5-15 \mathrm{mg} / \mathrm{dm}^{3}$ ) and also $\mathrm{NaCl}$ solutions. The volumetric technique was used for flux measurements. The concentration was measured by conductometric technique.

Results and discussion. The membrane resistance during reverse osmosis of deionized water did not change with applied pressure in experimental conditions and was equal $R_{m}=7,549 \cdot 10^{13} \mathrm{~m}^{-1}$.

The concentration polarization layer resistance $\left(R_{c p}\right)$ increased from $0.65-1.29 \cdot 10^{13} \mathrm{~m}^{-1}$ to $1.46-1.83 \cdot 10^{13} \mathrm{~m}^{-1}$ with applied pressure increasing from $0.2 \mathrm{MPa}$ to $0.6 \mathrm{MPa}$ and from $0.65-1.46 \mathrm{~m}^{-1}$ to $1.29-1.83 \cdot 10^{13} \mathrm{~m}^{-1}$ with increasing of feed concentration from $100 \mathrm{mg} / \mathrm{dm}^{3}$ to $600 \mathrm{mg} / \mathrm{dm}^{3}$. This increasing of $R_{c p}$ value with pressure was linear which is in agreement with previously reported data for the ultrafiltration process. Moreover, in considered range of applied pressure, the exponential dependence of index of concentration polarization from applied pressure could be approximated by a linear equation with correlation coefficient 0.93. Therefore, assumption about linear dependence of concentration polarization layer resistance from pressure is reasonable and could be extended to reverse osmosis process for mentioned above conditions.

The increasing of concentration polarization layer resistance with increasing of applied pressure is determinated by higher values of transmembrane fluxes and lower values of mass transfer coefficient at higher values of applied pressure in the considered system. These results are in agreement with film theory of concentration polarization.

Conclusions. The exanimated hypothesis is validated for reverse osmosis in considered range of applied pressure. The correlation between concentration polarization layer resistance and index of concentration polarization was defined. 


\section{Introduction}

The concentration polarization phenomenon and the scaling formation on membrane surface are the main problems in using of pressure-driven membrane processes in the food industry. In particular, during drinking water production with using of microfiltration and ultrafiltration the water flux decrease almost twice (from $102 \mathrm{dm}^{3} / \mathrm{h}$ until $50 \mathrm{dm}^{3} / \mathrm{h}$ ) due to those effects [1], moreover, flux drop is observed also in case of membranes with antifouling modification [2] and membrane systems with pretreatment [3]. During pomegranate juice ultrafiltration the resistance of cake layer was $35.6-56.9 \%$ of the total resistance of mass transfer across the membrane which causes the dramatic drop of permeate flux [3], similar results was obtained for ultrafiltration of bergamot and kiwifruit juices [5]. During nanofiltration and reverse osmosis of milk whey, the rapid flux drop due to adsorption fouling and following flux decreasing due to concentration polarization and cake layer formation was observed [6]. In case of milk whey ultrafiltration flux drop for $67.5 \%$ because of those phenomena was observed over 20 hours of work [7] and during skimmed milk microfiltration the cake layer resistance was two times higher than membrane resistance [8]. Significant decreasing of permeate flux was also defined for microfiltration such products as corn distillery [9], beer [10] and wine [11].

The comprehensive review of mentioned phenomena was carried out by Shirazi and al. [12]. In particular, in that work, it was pointed out that decreasing in permeate flux is determinated by series resistances of mass transfer across the membrane which include membrane resistance, concertation polarization resistance, cake later resistance and pore blocking resistance. However, pore blocking resistance is not significant for most of the pressure-driven membrane process therefore in others works, for example, Luo and al [13] for investigation of nanofiltration processes and Macedo and al. [14] for analysis of ultrafiltrations, only the first three resistances were taken into account.

The methods for determination of membrane resistance and cake layer resistance are represented in works [12-14], moreover, Sioutopoulos and Karabelas [15] have determinated the dependences of fouling layer resistance from working parameters of ultrafiltration process in particular from applied pressure. But methods for determination of concentration polarization layer resistance are almost not described in the literature.

In most cases, the researches of concentration polarization have theoretical character and looked toward for development and assess the adequacy of mathematical models of that phenomena. For example, Geraldes and Afonso [16] have proposed the model based of extended Nernst-Planck equation, which allows to predict the parameters of concentration polarization (index of concentration polarization) for the case of nanofiltration and reverse osmosis of diluted multicomponent salt solutions. Song and Liu [17] have developed the model based on general salt balance and shear stress. Cavaco Morao and al. [18] have used for simulation the method of computational fluid dynamics (CFD). Kim and Hoek [19] have carried out the comparison of several analytical and numerical models for prediction of concentration polarization and have defined their satisfied accuracy in the range of operating parameters change which correspond to the real condition of reverse osmosis process operation. But in these works, the value of concentration polarization as such are not considered.

Shirazi and al. [12] have pointed out that for taking into account the concentration polarization layer resistance it is possible to use of mediate methods as it has been done in earlier works [20-22], in particular, Song [22] has pointed out, that influence of concentration polarization could be taken into account by decreasing of driving force. he most comprehensive study of the problem of concentration polarization layer resistance has been 
carried out by Macedo and al [14]. They declare that under constant solute concentration, feed flow velocity and temperature, concentration polarization layer resistance depend from applied pressure, in particular, the assumption about the linear dependence between these values. But this hypothesis has been verified only for ultrafiltration and for one kind of feed solution - ovine milk whey. The values of the proportional coefficient in work [14] have been determinated from experiments and their magnitudes have varied more than three times under different condition of the ultrafiltration process. Moreover, the physical meaning of the proportional coefficient has not been disclosed. Therefore, at present time the possibility of direct taking into account of concentration polarization resistance during calculation of membrane equipment is overstructured. Simultaneously Macedo and al. [14] have proposed the technique of data analysis of productivity of pressure-driven membrane processes, which allows to determinate the fouling layer resistance. In a case of availability of reliable dependence for concentration polarization layer resistance, this technique would allow to determinate in working conditions the necessity of regeneration of membranes. For this reason, the determination of this dependence is a topic of great practical significance.

The purpose of present work is the examination of hypothesis about linear dependence of concentration polarization layer from applied pressure in case of reverse osmosis of salt solutions and determination of applied pressure and also hydrodynamic conditions on concentration polarization resistance value.

\section{Materials and methods}

\section{Materials}

The experiments were carried out with using of commercially available reverse osmosis membrane modules Dow Filmtec TW30-1812-50 (made in USA). The deionized water (reverse osmosis permeate with total dissolved solids (TDS) 5-15 ppm which correspond to the concentration of Sodium Chloride $(\mathrm{NaCl}) 5-15 \mathrm{mg} / \mathrm{dm}^{3}$ ) and also $\mathrm{NaCl}$ solutions were used as feed solutions. The deionized water was used for measurements of membrane resistance and salt solution for measurements of concentration polarization layer resistance. The considered type of membrane modules is designed for tap water advanced treatment [23], for this reason for determination of concentration polarization layer resistance the solution which simulated TDS of tap water were used. According to [24] the overall mineralization in waters of Dnipro and Desna is $268-270 \mathrm{mg} / \mathrm{dm}^{3}$, and TDS parameter of tap water in European countries (Spain, Italy, and France) according to [25-26] is in range 70-820 ppm, in most cases this parameter was in range $100-600 \mathrm{ppm}$. Therefore, the $\mathrm{NaCl}$ solutions with concentrations of 100, 200, 400 and $600 \mathrm{mg} / \mathrm{dm}^{3}$ were used in experiments.

\section{Description of experimental set-up}

The existing experimental set-up (Figure 1) was used for carrying out experimental research. The set-up provides the measurements of permeate and retentate flow rate by volumetric technique through the use of tanks 5 and 6 with accuracy of $\pm 2 \mathrm{ml}$ and $\pm 10 \mathrm{ml}$ correspondingly (it was carried out the direct measurements of volume and time), and also it allows to measure the overall mineralization using portable TDS-meter with accuracy of 1 $\mathrm{mg} / \mathrm{dm}^{3}$. The applied pressure was measured by manometer 9 , the temperature was controlled by Chromel-Copel thermocouples and software module IndexTem with the accuracy of 0.2 ${ }^{\circ} \mathrm{C}$ (it did not represented on the scheme). 


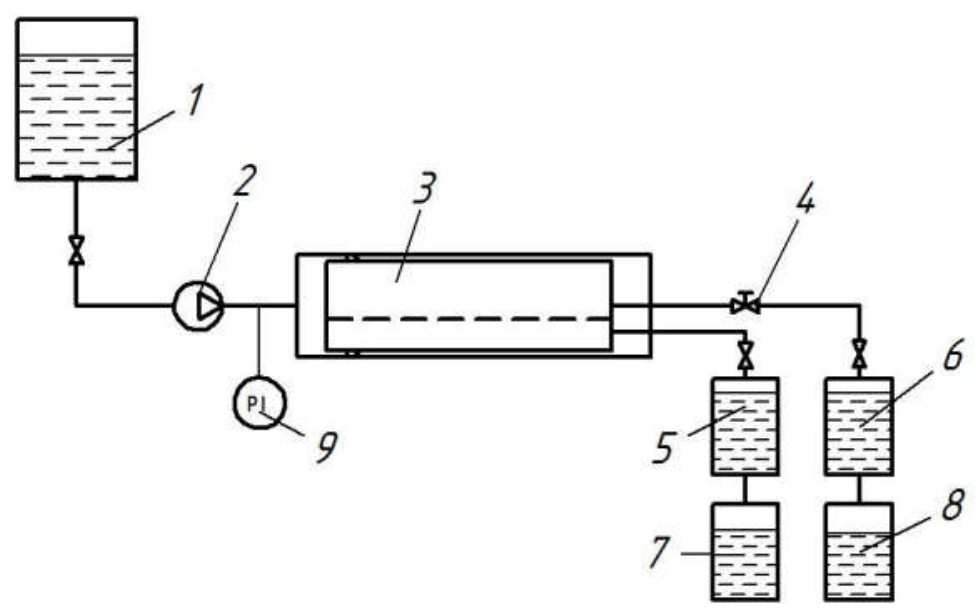

Figure 1. Scheme of experimental set-up:

1 - feed solution tank, 2 - pump, 3 - membrane unit, 4 - regulation valve, 5 - measuring tank for permeate, 6 - measuring tank for retentate, 7 - permeate collecting tank, 8 - retentate collecting tank, 9 - manometer.

\section{Procedure of carrying out the experiments and main measurements}

The feed solution was pumped with a predetermined pressure by pump 2 from tank 1 to plug flow membrane unit 3 in which the studied membrane module Dow Filmtec TW30-81250 was inserted. During the membrane separation process, the permeate (desalinated solution) and retentate (concentrated) solution were generated which flowed to measurement tanks 5 and 6 and gone on to collecting tanks 7 and 8 correspondingly. The applied pressure was regulated by the needle valve on the retentate line 4 and was controlled by manometer 9. The measurements of permeate and retentate were carried out by volumetric technique, according to it the volumes of solutions which simultaneously collected in measuring tanks 5 and 7 during the determined time interval (120 s) were determined.

\section{Processing the results of the research}

The feed solution flow rate was determ

inated from well-known material balance equations. The mass balance for streams is following [27]:

$$
L_{f}=L_{p}+L_{r}
$$

where $L_{f}$ is feed solution flow rate, $\mathrm{m}^{3} / \mathrm{s} ; L_{p}$ is permeate flow rate, $\mathrm{m}^{3} / \mathrm{s} ; L_{r}$ is retentate flow rate $\mathrm{m}^{3} / \mathrm{s}$.

The mass balance for the solute is following [27]:

$$
L_{f}=\frac{x_{p} L_{p}+x_{r} L_{r}}{x_{f}},
$$

where $x_{f}$ is solute concentration in feed solution, $\mathrm{mg} / \mathrm{dm}^{3} ; x_{p}$ is solute concentration in permeate, $\mathrm{mg} / \mathrm{dm}^{3} ; x_{r}$ is solute concentration in retentate, $\mathrm{mg} / \mathrm{dm}^{3}$. 
The mean values of determinated from equation (4) and (5) was used for further calculations. If the difference between that values was more than $5 \%$ the results obtained in such experiment were discarded as mistaken.

The transmembrane flux was determinated from the relationship [28]:

$$
J=\frac{L_{p}}{F},
$$

where $F$ is membrane surface area, $\mathrm{m}^{2}$; for the membrane module under consideration $F=0.46$ $\mathrm{m}^{2}$ (directly measured value).

The value of Reynolds number was used for analysis of hydrodynamic conditions in module [27]:

$$
\operatorname{Re}=\frac{w_{e} \cdot d_{e} \cdot \rho}{\mu} .
$$

Since in membrane module the flow rate change with channel length due to penetration of a part of the feed solution through the membrane in present research the mean value calculated from the permeate and retentate flow rate was used as a determining velocity, $\mathrm{m} / \mathrm{s}$ [27]:

$$
w_{e}=\frac{L_{f}+L_{r}}{2 \cdot S},
$$

where $S$ is membrane channel cross section, $\mathrm{m}^{2}$. For the membrane module under consideration $S=3.675 \cdot 10^{-4} \mathrm{~m}^{2}$ (directly measured value).

The equivalent diameter was used as determining linear dimension. For spiral wound membrane modules it can be represented in a form [28]:

$d_{e}=2 \cdot \delta,(6)$

where $\delta$ is spacer net width, $\mathrm{m}$.

\section{Determination of concentration polarization layer resistance}

The calculations of resistance were carried out based on transmembrane flux value which according to $[12-14]$ can be described by equation, $\mathrm{m}^{3} /\left(\mathrm{m}^{2} \cdot \mathrm{s}\right)$ :

$$
J=\frac{\Delta p-\Delta \pi}{\mu \cdot\left(R_{m}+R_{c p}+R_{f}\right)},
$$

where $\Delta p$ is applied pressure (driving force), $\mathrm{Pa} ; \Delta \pi$ is osmotic pressure of feed solution, $\mathrm{Pa}$; $\mu$ is coefficient of dynamic viscosity of feed solution, $\mathrm{Pa} \cdot \mathrm{s} ; R_{m}$ is membrane resistance, $\mathrm{m}^{-1}$; $R_{c p}$ is concentration polarization layer resistance, $\mathrm{m}^{-1}, R_{f}$ is fouling resistance.

In new membrane modules fouling is absent consequently in this case the value of $R_{f}$ will be equal to zero. Moreover, when deionized water is used as testing solution due to absence (or negligible amount) of solute the solution osmotic pressure $\Delta \pi$ would tend to zero and concentration polarization phenomena would not appear. Therefore, the membrane resistance can be defined from relationship [12]:

$$
R_{m}=\frac{\Delta p}{\mu \cdot J} .
$$

For thin-film composite membrane the flux drop due to compaction of membrane structure according to [29] is observed under applied pressures of 0.5-1.45 MPa. Although in current study in particular cases the applied pressure was in mentioned above range, the duration of continuous operation was no longer than 180-300 s, therefore it may assume that 
impact of compaction to membrane resistance was negligible. When this assumption is correct the $R_{m}$ will be constant under any applied pressure [12].

For the case of salt solution separation thorough new membrane, the total membrane resistance would be the sum of $R_{m}$ and $R_{c p}$ values. Whereas the $R_{m}$ is known, the concentration polarization resistance could be obtained from measurements results from dependency, found from the transformations of equations (7) and (8):

$$
R_{c p}=\frac{\Delta p-\Delta \pi}{\mu \cdot J}-R_{m} .
$$

Thus, for the solution with known values of osmotic pressure and dynamic viscosity the concentration polarization layer resistance could be determinated experimentally. The values of $\Delta \pi$ and $\mu$ depends on sort of substances (chemical composition of solution) and also they are functions of temperature and pressure. For monocomponent solutions, these values could be determinated from reference literature [30-31].

\section{Results and discussion}

The total resistance to mass transfer through the membrane was determinated on the results of the current study in the range of applied pressure of $\Delta p=0.2 . .0 .6$ for deionized water and $\mathrm{NaCl}$ solutions with concentration 100, 200, 400 and $600 \mathrm{mg} / \mathrm{dm}^{3}$ (Figure 2). The step of applied pressure variation was $0.1 \mathrm{MPa}$. In the case of deionized water, the deviation of total resistance values was less than $5 \%$ from the mean value which does not exceed of measurement error limit. Thus, the result shown that membrane resistance is constant and independent from applied pressure and the proposed assumption is confirmed. The mean value was $R_{m}=7.549 \cdot 10^{13} \mathrm{~m}^{-1}$ and this magnitude was used in further calculations.

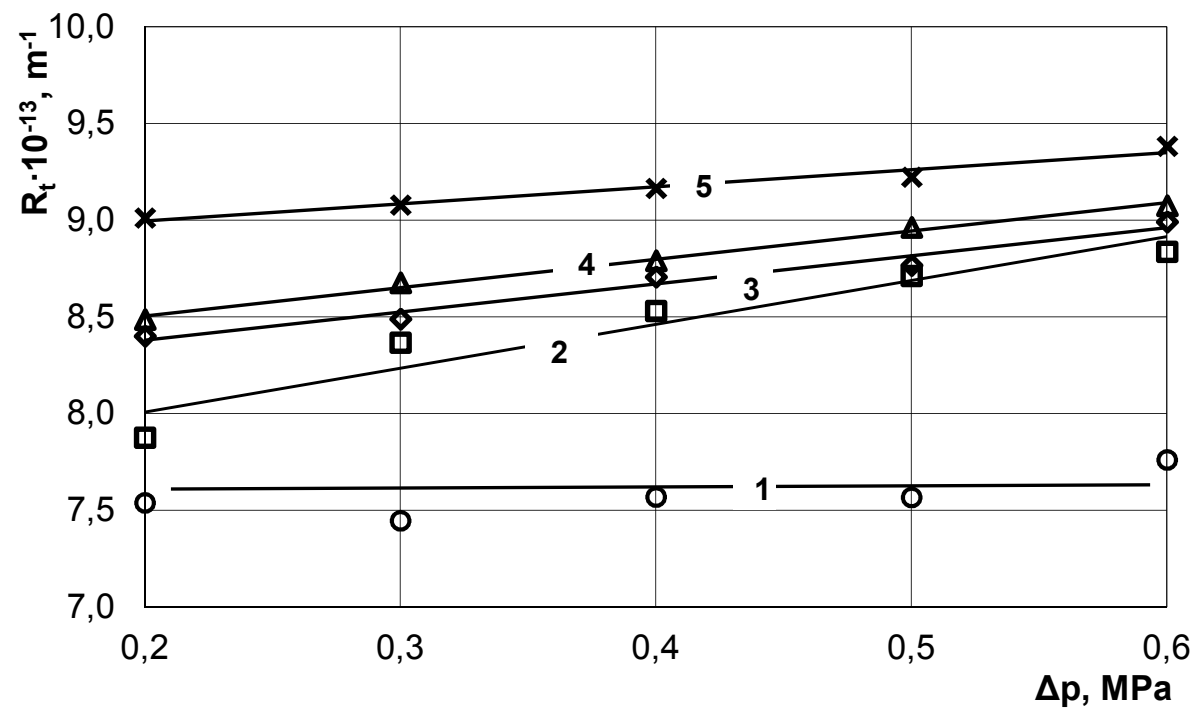

Figure 2. The dependence of total resistance to mass transfer thorough the membrane from applied pressure:

1 - Deionized water; $2-\mathrm{NaCl}$ solution, $100 \mathrm{mg} / \mathrm{dm}^{3} ; 3-\mathrm{NaCl}$ solution, $200 \mathrm{мг} /$ дм$^{3}$; $4-\mathrm{NaCl}$ solution, $400 \mathrm{mg} / \mathrm{dm}^{3} ; 5-\mathrm{NaCl}$ solution, $600 \mathrm{mg} / \mathrm{dm}^{3}$ 
During $\mathrm{NaCl}$ solutions separation using the membranes of consideration the total resistance increased with increasing of feed concentration, and applied pressure. Since the new membrane modules were used in experiments and $\mathrm{NaCl}$ concentration was lower than saturation limit on two orders of magnitude [30], the fouling resistance could be considered as absent, therefore total resistance increasing was determinated by concentration polarization. The concentration polarization layer resistance calculated using equation (9) is shown on Figure 3.

Thus, the equation (9) allow to determinate concentration polarization during reverse osmosis of salt solution. In order to validation of obtained results reliability, it is necessary to analyze them on the agreement with received theoretical foundations.

The increasing of concentration polarization resistance with feed concentration increasing is excepted and determinated by increasing in a corresponded number of times of concentration in boundary layer near membrane which reduce diffusion mass transfer toward membrane and increase driving for on reverse diffusion flow [12].

The increasing on concentration polarization layer resistance with applied pressure increasing is in agreement with results obtained in work [14]. In the considered range of applied pressure, this dependence could be approximated by a linear equation. For validation of such results on the agreement with existing received theoretical foundations about the influence of applied pressure on parameters of concentration polarization should be considered.

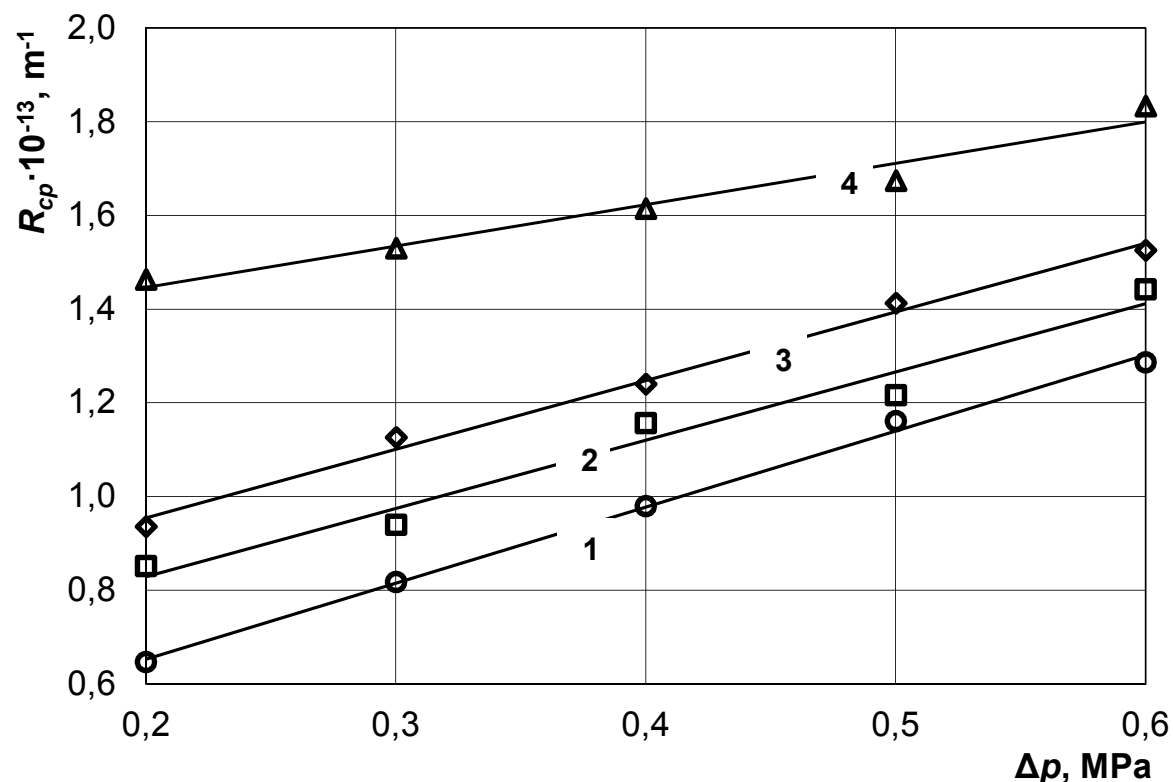

Figure 3. Dependence of concentration polarization layer resistance from applied pressure: $1-\mathrm{NaCl}$ solution, $100 \mathrm{mg} / \mathrm{dm}^{3} ; 2-\mathrm{NaCl}$ solution, $200 \mathrm{mg} / \mathrm{dm}^{3}$;

$3-\mathrm{NaCl}$ solution, $400 \mathrm{mg} / \mathrm{dm}^{3} ; 4-\mathrm{NaCl}$ solution, $600 \mathrm{mg} / \mathrm{dm}^{3}$ 
According to film theory of concentration polarization $[14,28]$ for evaluation of concentration polarization influence the value of the index of concentration polarization is used:

$$
f=\frac{c_{m}}{c_{b}}=\exp \left(\frac{J}{k}\right),
$$

where $c_{m}$ is solute concentration in boundary layer near membrane surface; $c_{b}$ is solute concentration in bulk of feed solution; $k$ is mass transfer coefficient.

In a case of nonideal selectivity equation (10) should be rewritten in the form [28]:

$$
f=\frac{c_{m}}{c_{b}}=\frac{\exp \left(\frac{J}{k}\right)}{\phi-(\phi-1) \cdot \exp \left(\frac{J}{k}\right)} .
$$

At that the rejection coefficient (selectivity) is determinated as [28]:

$$
\phi=1-\frac{c_{p}}{c_{f}},
$$

where $c_{p}$ is solute concentration in permeate, $\mathrm{kg} / \mathrm{m}^{3} ; c_{f}$ is solute concentration in feed solution, $\mathrm{kg} / \mathrm{m}^{3}$.

As mentioned in $[12,28]$ the index of concentration polarization value and correspondingly concentration in the boundary layer, increase with transmembrane flux increasing and mass transfer coefficient decreasing. Increasing of applied pressure determinate increasing of transmembrane flux (Figure 4) which govern the increasing of the index of concentration polarization that correlated with increasing of resistance in this layer (Figure 5).

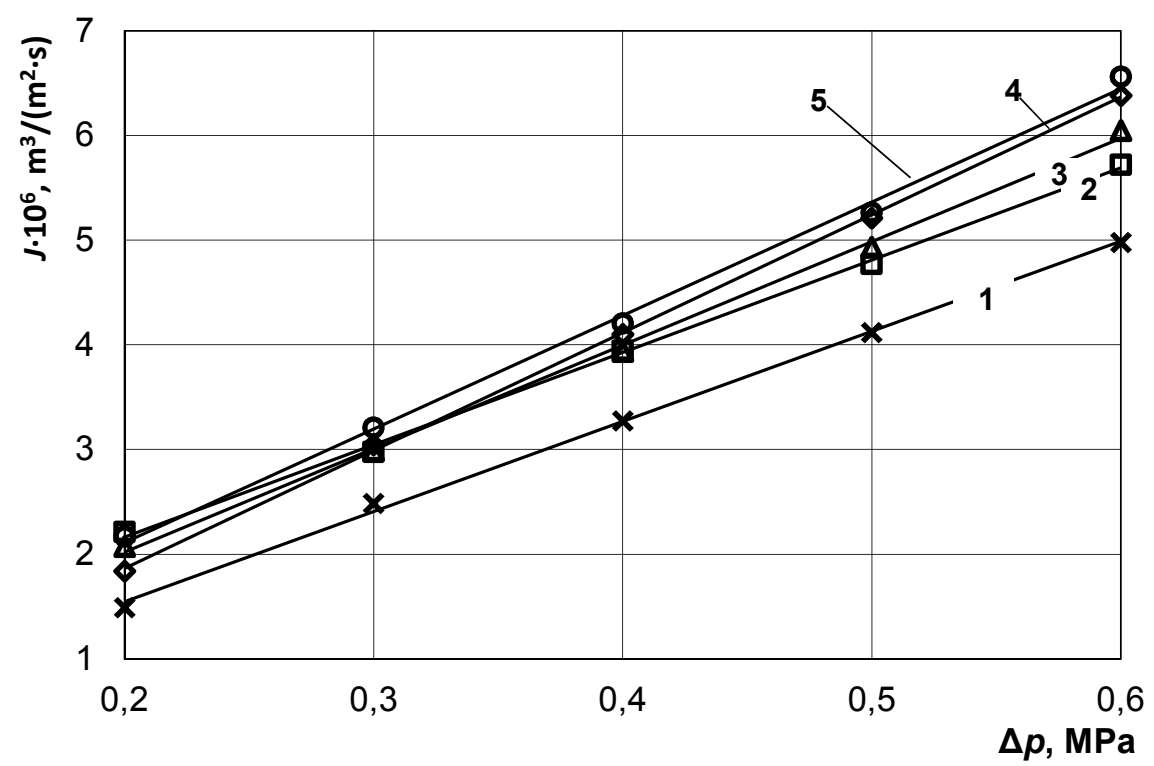

Figure 4. Dependence of transmembrane flux from applied pressure:

1 - Deionized water; $2-\mathrm{NaCl}$ solution, $100 \mathrm{mg} / \mathrm{dm}^{3} ; 3-\mathrm{NaCl}$ solution, $200 \mathrm{мг} /$ дм$^{3}$; $4-\mathrm{NaCl}$ solution, $400 \mathrm{mg} / \mathrm{dm}^{3} ; 5-\mathrm{NaCl}$ solution, $600 \mathrm{mg} / \mathrm{dm}^{3}$ 


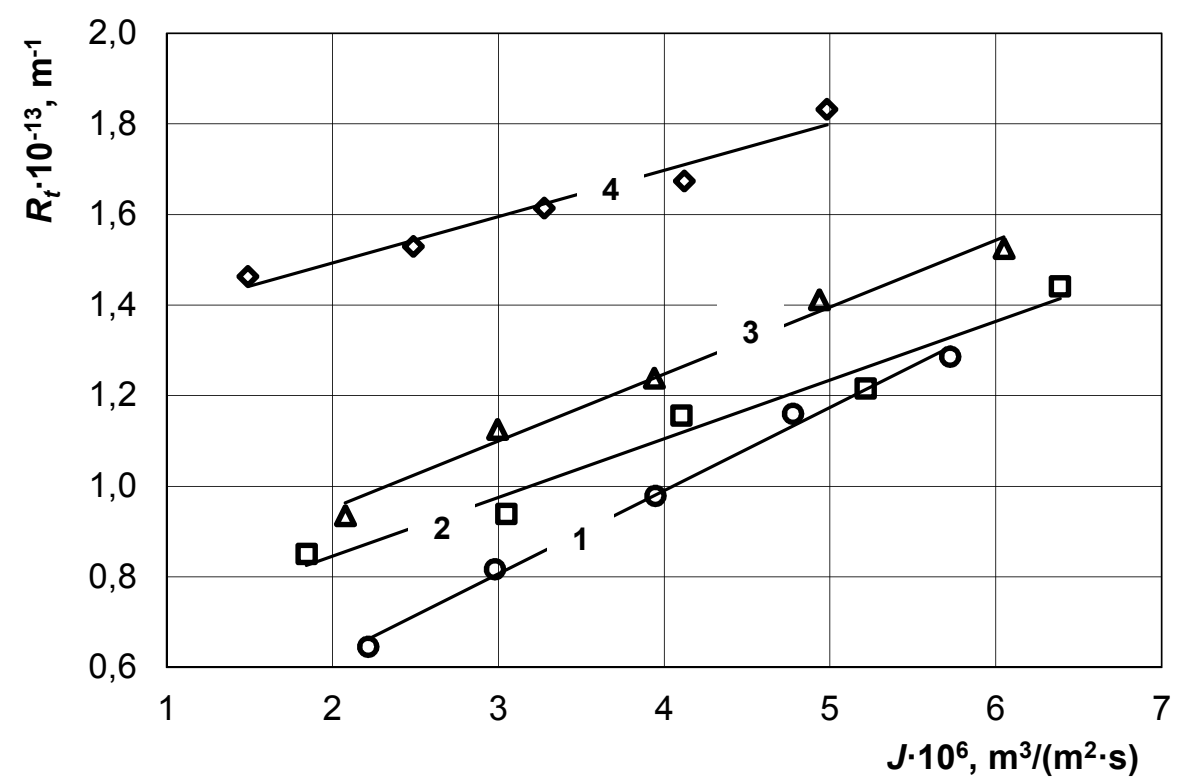

Figure 5. Dependence of concentration polarization resistance to mass transfer thorough the membrane from transmembrane flux:

$1-\mathrm{NaCl}$ solution, $100 \mathrm{mg} / \mathrm{dm}^{3} ; 2-\mathrm{NaCl}$ solution, $200 \mathrm{mg} / \mathrm{dm}^{3}$;

$3-\mathrm{NaCl}$ solution, $400 \mathrm{mg} / \mathrm{dm}^{3} ; 4-\mathrm{NaCl}$ solution, $600 \mathrm{mg} / \mathrm{dm}^{3}$

It should be noticed that experiments were carried out under an ambient temperature which varied from $10^{\circ} \mathrm{C}$ to $17^{\circ} \mathrm{C}$. This fact determinated observed deviation from decreasing of transmembrane flux with feed concentration increasing due to different values of dynamic viscosity of the solvent.

The mass transfer coefficient value depends on many factors, in particular, from hydrodynamic conditions in a membrane module and physical properties of a feed solution. Generally this parameter is calculated using dimensionless equations according to which increasing of liquid flow velocity (increasing of Reynolds number value) determinate increasing of mass transfer coefficient $[12,28]$. The dependence of Reynolds number from applied pressure is shown on Figure 6.

In experimental research processing the applied pressure was regulated by variation of hydrodynamic resistance of retentate flow and under such conditions, higher values of applied pressure correspond to higher Reynolds number values. Furthermore, concentration polarization resistance decreases with Reynolds number increasing (Figure 7). Correspondingly increasing of applied pressure in the involved system lead to decreasing of mass transfer coefficient decreasing which determinate increasing of the index of concentration polarization and in this case concentration polarization resistance also should increase. Therefore, the obtained experimental results are in generally in qualitative agreement with film theory of concentration polarization. 


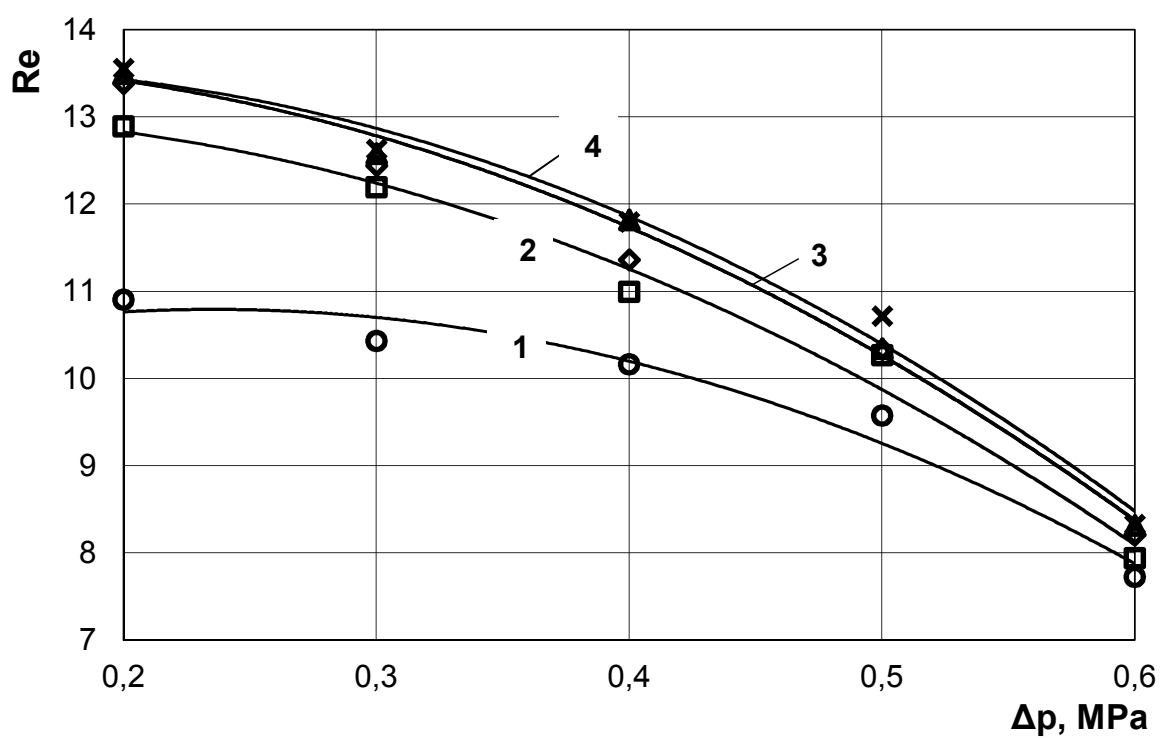

Figure 6. Dependance of Reynolds number from applied pressure:

$1-\mathrm{NaCl}$ solution, $100 \mathrm{mg} / \mathrm{dm}^{3} ; 2-\mathrm{NaCl}$ solution, $200 \mathrm{mg} / \mathrm{dm}^{3}$;

$3-\mathrm{NaCl}$ solution, $400 \mathrm{mg} / \mathrm{dm}^{3} ; 4-\mathrm{NaCl}$ solution, $600 \mathrm{mg} / \mathrm{dm}^{3}$

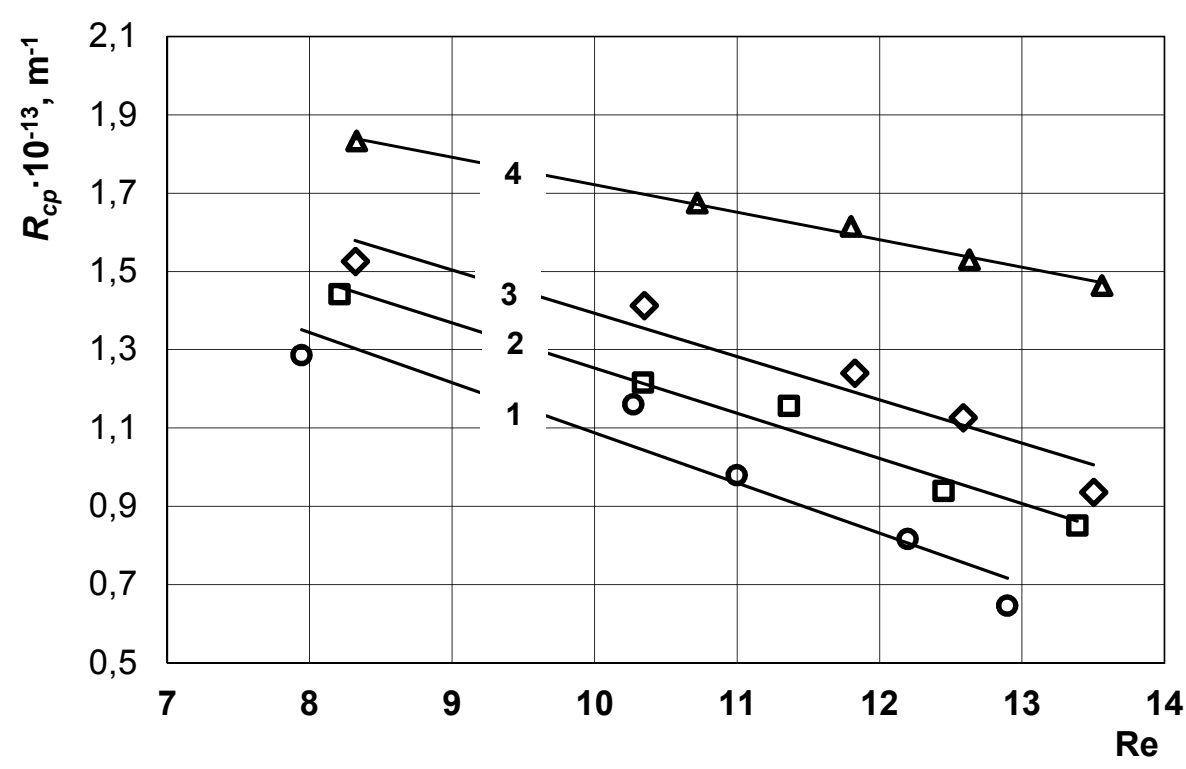

Figure 7. Dependence of concentration polarization layer resistance to mass transfer thorough the membrane from Reynolds number:

$1-\mathrm{NaCl}$ solution, $100 \mathrm{mg} / \mathrm{dm}^{3} ; 2-\mathrm{NaCl}$ solution, $200 \mathrm{mg} / \mathrm{dm}^{3}$;

$3-\mathrm{NaCl}$ solution, $400 \mathrm{mg} / \mathrm{dm}^{3} ; 4-\mathrm{NaCl}$ solution, $600 \mathrm{mg} / \mathrm{dm}^{3}$ 
It should be noticed that the dependence of concentration polarization layer resistance from Reynolds number could be approximated by a linear equation. The different values of Reynolds number under the same values of applied pressure are explained by different values of transmembrane flux for different feed solution concentration which determinated differences in retentate flux and correspondingly changes in determinated velocity calculated from equation (5).

In order to more reliable validation of defined results agreements with film theory, it should compare the variations of concentration polarization layer directly with the index of concentration polarization value. At that, since the experiments were carried out in range of Reynolds number $[7.9,13.5]$ which corresponds to the laminar regime of flow, the mass transfer coefficient values were estimated using the dimensionless equation for laminar flow in channel [28]:

$$
\mathrm{Sh}=\frac{k \cdot d_{e}}{D}=1,85 \cdot\left(\operatorname{Re} \cdot \mathrm{Sc} \cdot \frac{d_{e}}{L}\right)^{0,33},
$$

where $D$ is diffusivity, $\mathrm{m}^{2} / \mathrm{s} ; \mathrm{Sc}=v / D$ is Schmidt number; $L$ is channel length, $\mathrm{m} ; v$ is coefficient of kinematic viscosity, $\mathrm{m}^{2} / \mathrm{s}$.

The length of considered channel was $L=0.26 \mathrm{~m}$ (directly measured value), the value of coefficient of kinematic viscosity was determinated using reference literature [30-31] and diffusivity value were calculated using the Wilke-Chang equation [27]:

$$
D=5,06 \cdot 10^{-11} \frac{T_{s}}{\mu_{l} \cdot V_{s}}
$$

where $T_{S}$ is solvent absolute temperature, $\mathrm{K} ; \mu_{l}$ is solvent coefficient of dynamic viscosity, $\mathrm{mPa} \cdot \mathrm{s} ; V_{s}$ is solute molar volume, $\mathrm{cm}^{3} / \mathrm{mole}$.

The values of the index of concentration polarization were calculated using equation (11), all parameters were determinated from the results of measurements. The dependence of concentration polarization index from applied pressure is shown on Figure 8 .

The values of the index of concentration polarization according to equation (11) increase exponentially but in regarding range of applied pressure change this dependence could be approximated by a linear equation with sufficient accuracy for engineering calculation. In particular, for $\mathrm{NaCl}$ concentration of $200 \mathrm{mg} / \mathrm{dm}^{3}$, the sample correlation coefficient is 0.97 . Therefore, the assumption about linear dependance of concentration polarization layer resistance from applied pressure in several ranges of this parameter presented in work [14] is reasonable and could be used not only for a case of ultrafiltration and also for reverse osmosis.

It should be noticed that concentration polarization layer resistance increase in 1,25-2 times when applied pressure increase from 0.2 to $0.6 \mathrm{MPa}$ (Figure 3). The index of concentration polarization in this case increase in 1.9-2.15 times (Figure 8). Moreover, the relationship between concentration polarization layer resistance and index of concentration polarization could be approximated by a linear equation with correlation coefficients more than 0.93 (Figure 9). 


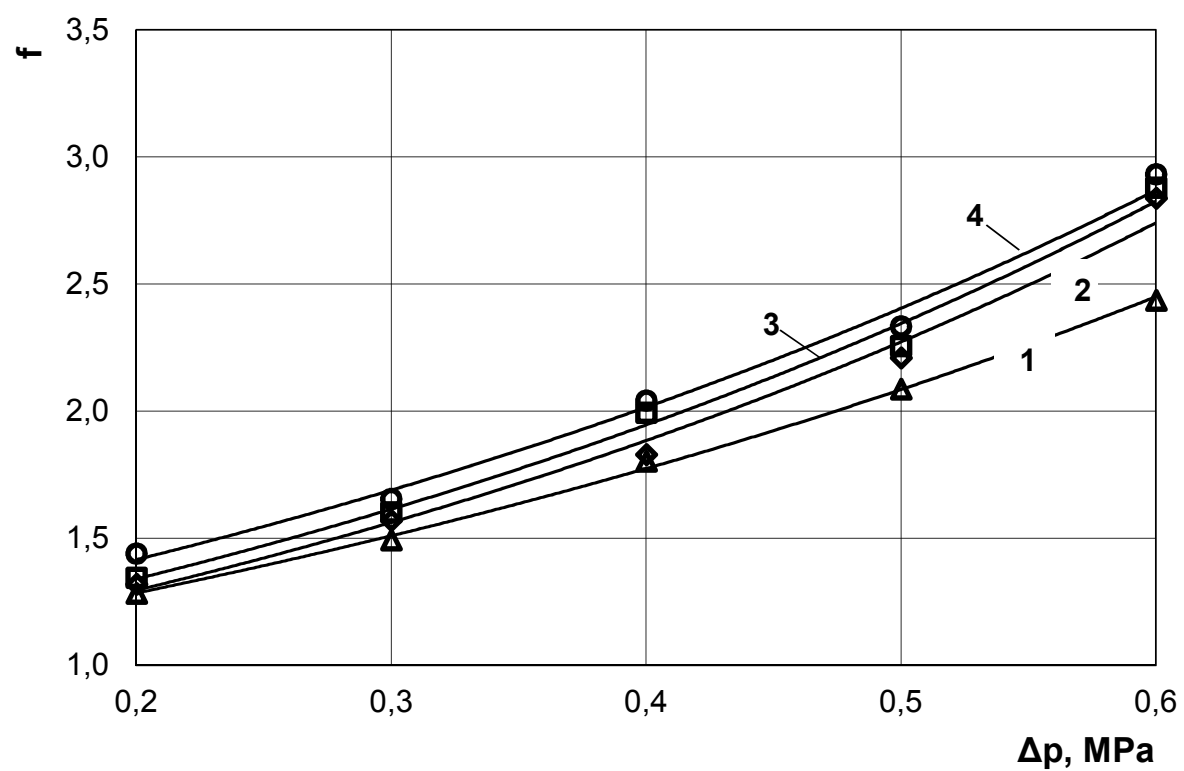

Figure 8. Dependence of index of concentration polarization from applied pressure $1-\mathrm{NaCl}$ solution, $100 \mathrm{mg} / \mathrm{dm}^{3} ; 2-\mathrm{NaCl}$ solution, $200 \mathrm{mg} / \mathrm{dm}^{3}$;

$3-\mathrm{NaCl}$ solution, $400 \mathrm{mg} / \mathrm{dm}^{3} ; 4-\mathrm{NaCl}$ solution, $600 \mathrm{mg} / \mathrm{dm}^{3}$

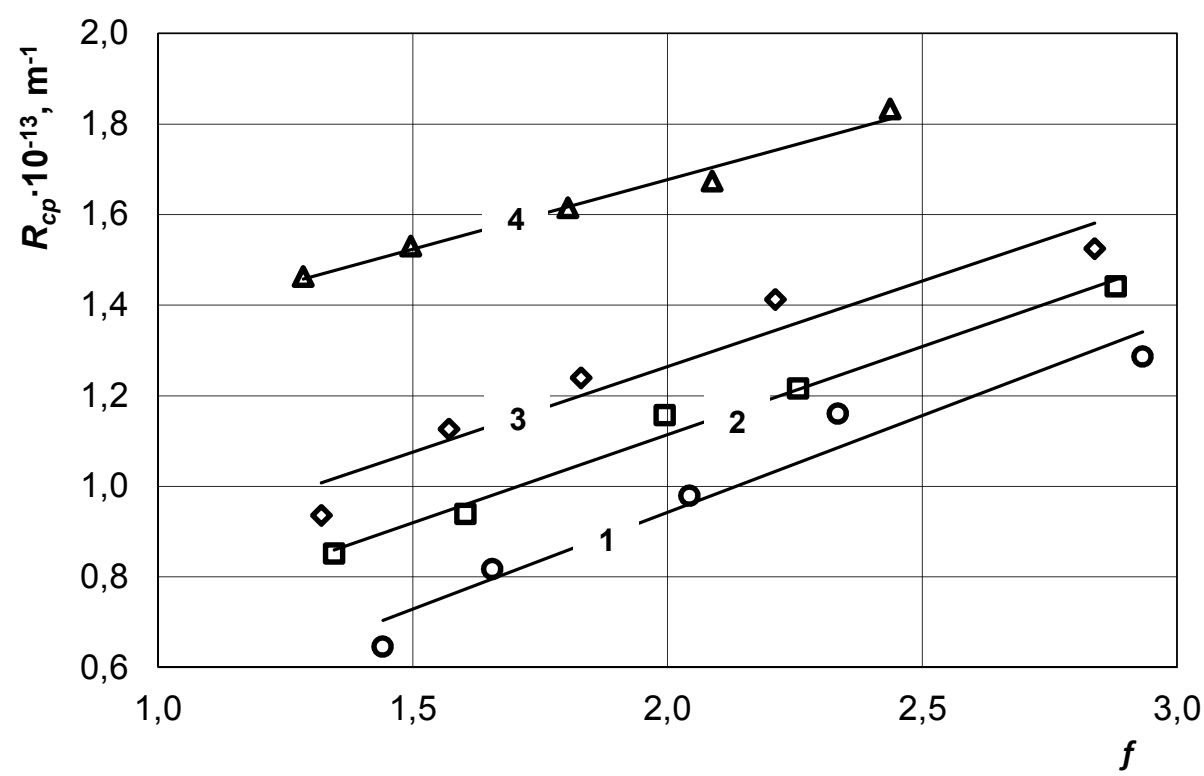

Figure 9. Dependence of concentration polarization layer resistance to mass transfer thorough the membrane

$1-\mathrm{NaCl}$ solution, $100 \mathrm{mg} / \mathrm{dm}^{3} ; 2-\mathrm{NaCl}$ solution, $200 \mathrm{mg} / \mathrm{dm}^{3}$;

$3-\mathrm{NaCl}$ solution, $400 \mathrm{mg} / \mathrm{dm}^{3} ; 4-\mathrm{NaCl}$ solution, $600 \mathrm{mg} / \mathrm{dm}^{3}$ 
Consequently, such good qualitative agreement of concentration polarization layer resistance calculated from equation (9) with well-known theoretical fundamentals confirms the possibility of using the before-mentioned technique in serial experiments. The results obtained from pilot experiments are not enough for the establishment of quantitative relationships among concentration polarization layer resistance and operating parameters including applied pressure. Also, this data are not enough for the determination of proportional coefficient which used in work [14]. Thus, the further investigation is necessary which would allow obtaining the reliable calculation dependencies in form of functions of operating parameters of pressure driven membrane separation processes (applied pressure, feed solution properties, hydrodynamic condition in modules etc.)

\section{Conclusion}

1. The hypothesis about linear dependence of concentration polarization layer resistance from applied pressure which used for analysis of milk whey ultrafiltration process is confirmed for the case of salt solutions reverse osmosis in the range of applied pressure $0.2-0.6 \mathrm{MPa}$.

2. In the considered range of applied pressure, the influence of membrane compaction is negligible and it could be considered that applied pressure does not affect the membrane resistance value for the considered type of membrane.

3. The obtained qualitative dependences of concentration polarization layer dependences from applied pressure, transmembrane flux and Reynolds number are in agreement with film theory. Moreover, the correlation between concentration polarization layer resistance and index of concentration polarization which allows assuming about the possibility to obtain of reliable calculation dependence of concentration polarization layer resistance from operating parameters of pressure driven membrane separation processes.

\section{References}

1. Chang H., Liang H., Qu F., Liu B., Yu H., Du X., Li G., Snyder S. (2017), Hydraulic backwashing for low-pressure membranes in drinking water treatment: A review, Journal of Membrane Science, 540, pp. 262-380.

2. Du J., Peldszus S., Huck P., Feng X. (2015), Modification of membrane surfaces via microswelling for fouling control in drinking water treatment, Journal of Membrane Science, 475, pp. $488-495$.

3. Stoquart C., Servais P., Bérubé P., Barbeau B. (2012), Hybrid Membrane Processes using activated carbon treatment for drinking water: A review, Journal of Membrane Science, 411-412, pp. $1-12$.

4. Onsekizoglu P. (2013), Production of high quality clarified pomegranate juice concentrate by membrane processes, Journal of Membrane Science, 442, pp. 264-271.

5. Ruby-Figueroa R., Saavedra J., Bahamonde N., Cassano A. (2017), Permeate flux prediction in the ultrafiltration of fruit juices by ARIMA models, Journal of Membrane Science, 524, pp. 108116.

6. Kyrychuk I., Myronchuk V., Zmiievskii Y., Holiachuk S. (2015), Two-stage whey treatment by nanofiltration and reverse osmosis, Ukrainian Food Journal, 4 (4), pp. 638-647.

7. Chamberland J., Beaulieu-Carbonneau, Lessard M.-H., Labrie S., Bazinet L., Doyen A., Pouliot Y. (2017), Effect of membrane material chemistry and properties on biofouling susceptibility during milk and cheese whey ultrafiltration, Journal of Membrane Science, 542, pp. 208-216.

8. Jimenez-Lopez A.J.E., Leconte N., Garnier-Lambrouin F., Bouchoux A., Rousseau F., GésanGuiziou G. (2011), Ionic strength dependence of skimmed milk microfiltration: Relations between 
filtration performance, deposit layer characteristics and colloidal properties of casein micelles, Journal of Membrane Science, 369, pp. 404-413.

9. Zmievskii Y., Dziazko Y., Myronchuk V., Rozhdestvenska L., Vilenskii A., Kornienko L. (2016), Fouling of polymer and organic-inorganic membranes during filtrarion of corn distillery, Ukrainian Food Journal, 5 (4), pp. 739-747.

10. van der Sman R.G.M., Vollebregt H.M., Mepschen A., Noordman T.R. (2012), Review of hypotheses for fouling during beer clarification using membranes, Journal of Membrane Science, 396, pp. 22-31.

11. El Rayess Y., Albasi C., Bacchi P., Taillandi P., Mietton-Peuch M., Devatine A. (2011), Crossflow microfiltration of wine: Effect of colloids on critical fouling conditions, Journal of Membrane Science, 385-386, pp. 177-186.

12. Shirazi S., Lin C.-J., Chen D. (2010), Inorganic fouling of pressure-driven membrane processes A critical review, Desalination, 250, pp. 236-248.

13. Luo J., Ding L., Su Y., Wei Sh., Wan Y. (2010), Concentration polarization in concentrated saline solution during desalination of iron dextran by nanofiltration, Journal of Membrane Science, 363, pp. $170-179$.

14. Macedo A., Duarte E., Pinho M. (2011), The role of concentration polarization in ultrafiltration of ovine cheese whey, Journal of Membrane Science, 381, pp. 34-40.

15. Sioutopoulos D., Karabelas A. (2015), The effect of permeation flux on the specific resistance of polysaccharide fouling layers developing during dead-end ultrafiltration, Journal of Membrane Science, 473, pp. 292-301.

16. Geraldes V., Afonso M. D. (2007), Prediction of the concentration polarization in the nanofiltration/reverse osmosis of dilute multi-ionic solutions, Journal of Membrane Science, 300, pp. 20-27.

17. Song L., Liu C. (2012), A total salt balance model for concentration polarization in crossflow reverse osmosis channels with shear flow, Journal of Membrane Science, 401-402, pp. 313-322.

18. Cavaco Morao A., Brites Alves A., Geraldes V. (2008), Concentration polarization in a reverse osmosis/nanofiltration plate-and-frame membrane module, Journal of Membrane Science, 325, pp. 580-591.

19. Kim S., Hoek E. (2005), Modeling concentration polarization in reverse osmosis processes, Desalination, 186, , pp. 111-128.

20. van Den Berg G.B., Smolders C.A. (1990), Flux Decline in ultrafiltration process, Desalination, 77, pp. 101-133.

21. Wijmans J.G., Nakao S., Smolders C.A. (1984), Flux limitation in ultrafiltration: osmotic pressure model and gel layer model, Journal of Membrane Science, 20, pp. 115-124.

22. Song L. (1998), Flux decline in crossflow microfiltration and ultrafiltration: mechanisms and modeling of membrane fouling, Journal of Membrane Science, 139, pp. 183-200.

23. Weinman S., Fierce E., Husson S. (2019), Nanopatterning commercial nanofiltration and reverse osmosis membranes, Separation and Purification Technology, 209, pp. 646-657.

24. Kravchenko M.V. (2015), Fizyko-khimichnyi analiz pryrodnoi pytnoi vody riznykh dzherel vodopostachannia, Ekolohichna bezpeka ta pryrodokorystuvannia, 3(19), pp. 52-60.

25. Cidu R., Frau F., Tore P. (2011), Drinking water quality: Comparing inorganic components in botled water and Italian tap water, Journal of Food Composition and Analysis, 24, pp. 184-193.

26. Platikanov S., Hernández A., González S., Cortinac J.L., Tauler R., Devesa R. (2017), Predicting consumer preferences for mineral composition of bottled and tap water, Talanta, 162, pp. 1-9.

27. Thibodeaux L., Mackay D. (2011), Handbook of Chemical Mass Transport in the Environment, CRC Press, New York.

28. Mulder M. (2000), Basic principles of membrane technology, Kluwer academic publishers, Dordrecht.

29. Aghajani M., Wang M., Cox L., Killigore J., Greenbeng A., Ding Y. (2018), Influence of supportlayer deformation on the intrinsic resistance of thin film composite membranes, Journal of Membrane Science, 567, pp. 49-57.

30. Nikolskij B. (2013). Spravochnik himika tom 3. Himicheskoe ravnovesie i kinetika. svojstva. [S.1.]: Book On Demand Ltd.

31. Yaws C. (1999), Chemical properties handbook: physical, thermodynamic, environmental, transport, safety and heals related properties for organic and inorganic chevicals, McGraw-Hill, New York. 